\title{
Die ersten Frankfurter Zitrustage
}

\section{Alexander Becker}

Im Palmengarten fanden vom 30. Juni bis 2. Juli 2017 erstmals die Frankfurter Zitrustage statt. Im Fokus dieser Veranstaltung stand die Zitruspflanzen-Sammlung der Gärtnerei des Palmengartens. Im Palmenhaus wurden von dieser Sammlung etwa 60 verschiedene Sorten und Arten gezeigt. Auf Informationstafeln wurden die Besucher über Botanik, Herkunft, Orangerien und die Pflege dieser beliebten Pflanzengattung informiert. Wer Probleme mit seinen Zitruspflanzen oder spezielle Fragen hatte, konnte diese mit den zuständigen Gärtnern besprechen. Auf einer großen, mit Zitrusfrüchten und Blumen dekorierten „Festtafel“ standen auf der Palmenhausterrasse für alle Besucherinnen und Besucher verschiedene Zitrusfrüchte zur Verkostung bereit. Verschiedene Orangen, Kumquats, australische Fingerlimetten, Riesen-Zitronatzitronen und diverse andere Sorten, die es kaum im Handel zu erwerben gibt, wurden für den Gaumen bereitgestellt. Im Rahmenprogramm war unter anderem auch eine Cocktailbar zu finden. Max Martini kreierte dort Cocktails, in denen Zitrusfrüchte natürlich nicht fehlen durften. An beiden Tagen gab es einen Vortrag von Hilke Steinecke mit dem Titel: „Zitrus - Vielfalt, Kulturgeschichte und Symbolik“. Zudem fand eine Vorstellung eines Zitrusbuches statt. Andreas Honegger las aus seinem gerade frisch erschienenen Buch „Das kleine Buch der Zitruspflanzen“. Wer nun Lust auf eine eigene Zitruspflanze bekommen hat, der konnte am Verkaufsstand des Palmengartens entsprechende Pflanzen erwerben. Trotz des schlechten regnerischen Wetters wurde die Ausstellung sehr gut besucht und fand großen Anklang.

Ein großer Dank geht an die Freunde des Palmengarten e.V., mit deren finanzieller Unterstützung die ersten Frankfurter Zitrustage realisiert werden konnten. Für die Zukunft sind weitere Zitrus-Veranstaltungen geplant, so auch die große Zitrus-Informationsausstellung in 2019.

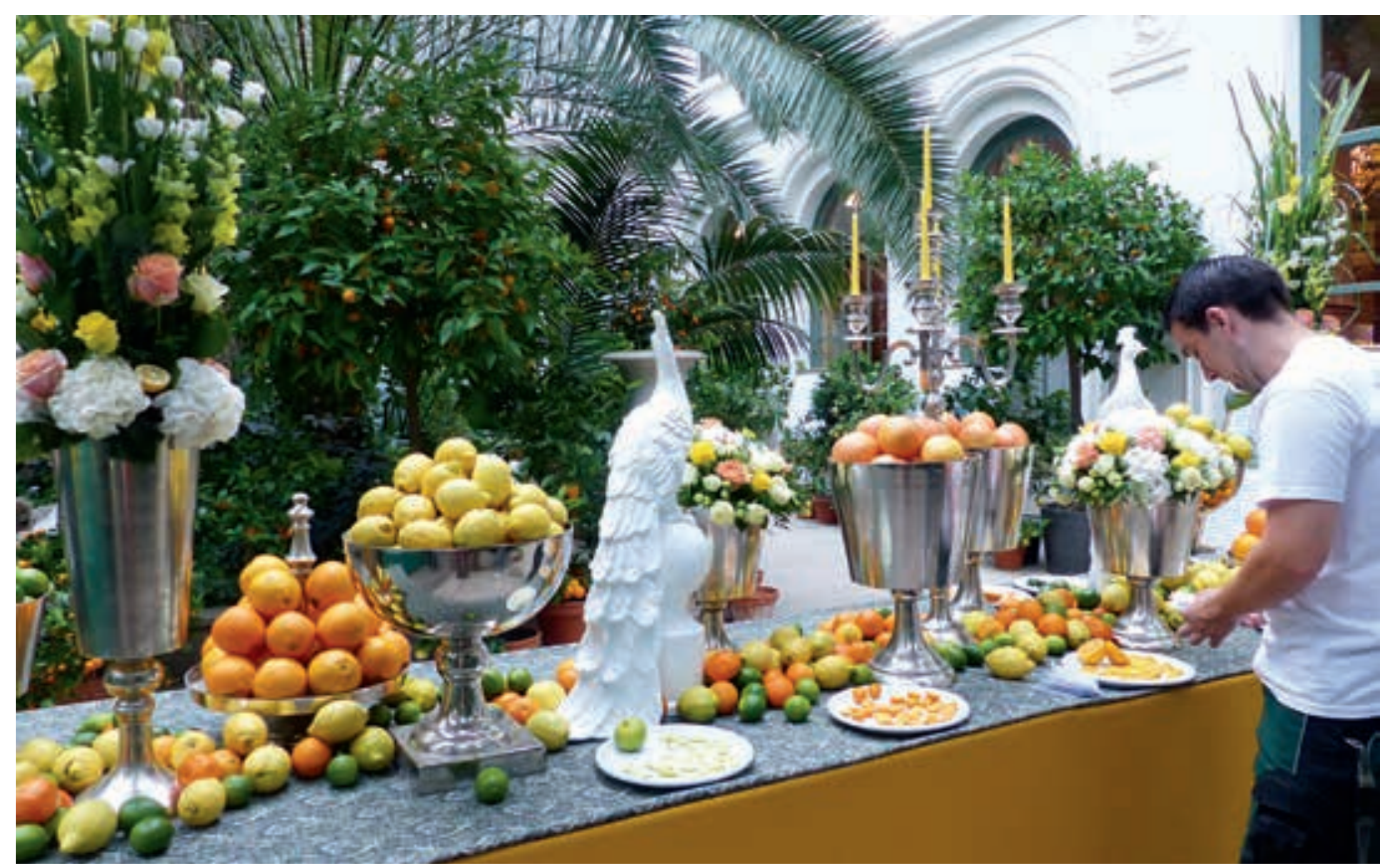

Zitrus-Präsentation auf der Palmenhausterrasse. 